\title{
MONITORING SOIL MOISTURE IN A COAL MINING AREA WITH MULTI-PHASE LANDSAT IMAGES
}

\author{
J. L. Kong ${ }^{\text {a, b* }}{ }^{*}$ T. Xian ${ }^{\text {a }}$, J. Yang ${ }^{\text {a }}$, L. Chen ${ }^{\text {a }}$, X. T. Yang ${ }^{\text {a }}$ \\ ${ }^{a}$ School of Earth Science and Resources, Chang'an University, 126 Yanta Road, Xi'an 710054, P.R. China - jlkong@163.com, \\ xianta05050@126.com, yjchdst@126.com, chenjw1199@126.com, yangxt1103@163.com \\ ${ }^{\mathrm{b}}$ Key Laboratory of Subsurface Hydrology and Ecology in Arid Areas (Chang'an University), Ministry of Education, Xi'an 710054, \\ P.R. China
}

Commission VII, WG VII/5

KEY WORDS: Monitoring soil moisture, Remote sensing retrieval, Landsat images, Ground surface deformation, Coal mining area

\begin{abstract}
:
The coal development zone of Northern Shaanxi, China is one of the eight largest coal mines in the world, also the national energy and chemical bases. However, the coal mining leads to ground surface deformation and previous studies show that in collapse fissure zone soil water losses almost 50\% compared with non-fissure zone. The main objective of this study is to develop a retrieval model that is reliable and sensitive to soil moisture in the whole coal mining zone of Northern Shaanxi based upon the soil sample parameters collected from in situ site investigation, spectral data gathered simultaneously and the images of Landsat7 ETM. The model uses different phases of Landsat data to retrieve soil moisture and analyze the patterns of spatial and temporal variations of soil moisture caused by ground deformation in the coal mining areas. The study indicated that band4 of Landsat7 ETM is the most sensitive band for soil moisture retrieval using the spectrum method. The quadratic model developed by remote sensing reflectance (Rrs4) (corresponding to the band4) is the best pattern with the correlation coefficient of 0.858 between the observed and the estimated soil moisture. Two-phase Landsat7 ETM data of 2002 and 2009 and one phase Landsat8 OLI data of 2015 for the study area were selected to retrieve soil moisture information. The result showed that the mean relative error was $35.16 \%$ and the root-mean-squared error (RMSE) was $0.58 \%$. The changes of the spatial distribution of inversed soil moisture revealed that the trend of soil moisture contents of the study area was in general being gradually reduced from 2002 to 2015. The study results can serve as the baseline for monitoring environmental impacts on soil moisture in the regions due to coal mining.
\end{abstract}

\section{INTRODUCTION}

The moisture storage in soil - vadose zone is the important components of natural water cycles, which has a close relationship with water - soil - plant system and plays an important role for the healthy development of ecological environment. The coal development zone of Northern of Shaanxi, China which is located in the middles of Yellow River and rich in coal resources, is one of the eight largest coal mines in the world, also the national energy and chemical bases. However, the region is a drought and water shortage area, and the ecological environment is fragile. Because the main aquifer is located above the coal seam, the free mining space is shaped after the coal mining with the rock masses moving and deformation around the space. This situation will spread from the overlying seam to the surface and causes subsidence, cracks in ground surface. Lead to massive losses of soil - vadose zone water and groundwater through cracks and collapses. In collapse fissure zone, soil water losses almost 50\% (Song, 2007) compared with non-fissure zone. As a result, it directly affects the plant growth and leads to the ecological environment destruction. The study on monitoring soil moisture in coal mining zone is enormously significant, for the restoration and protection of local ecological environment.

Traditional field measurement for soil moisture is complex, labour-intensive, expensive, and time-consuming. Only limited samples can be collected, and it is difficult to establish the area boundaries for different soil moisture fields. Remote-sensing techniques are promising to rapidly monitor regional soil moisture because of their spatially explicit measurements, almost real-time detection as well as their relatively low cost. Many methods have been developed and used to monitor soil moisture based on remote sensing technology (Moran et al., 2004, Jian et al., 2012, Mladenova et al., 2014, Sadeghi et al., 2015).

Early studies on soil samples in laboratory conditions showed that the reflectance in the wavelengths range $400-2500 \mathrm{~nm}$ decreased as the moisture content increased (Hoffer et al., 1969; Lobell et al., 2002). This general trend was first modeled with oven-dry soil samples at the wavelength of $1950 \mathrm{~nm}$ (Skidmore et al., 1975). However, retrieval soil moisture from remote sensing data remains rather difficult, as the soil reflectance is not just a function of moisture but is affected by intrinsic soil factors: amount of organic matter, particle size distribution, mineral composition, and color of soil elements (Escadafal et al., 1989; Hoffer et al., 1969; Hovis, 1966; Mattikalli, 1997; Stoner et al., 1981). Reflectance of soils depends also on the sun - target sensor geometry. Jaquemoud et al. (1992) developed the SOILSPEC radiative transfer model in the laboratory, which accounts for the soil roughness, the solar-view angle geometry, and the intrinsic optical properties of soils materials to compute soil bidirectional reflectance from 450 to $2450 \mathrm{~nm}$. The penetration of the signal is better in the thermal infrared and in the microwave domains and both domains have in some circumstances a better potential for monitoring the soil moisture

* Corresponding author: jlkong@163.com 
(Li et al., 2013, El-Hajj et al.,2014, Rincon et al., 2014, Han et al., 2015). Most models tested for the retrieval of soil moisture using optical and thermal infrared data (Leng et al., 2014), geostationary satellite data (Leng et al., 2015), surface shortwave radiation (Zhao et al., 2013), AMSR-E (Duan et al., 2014 \& Liu et al., 2014) or RADARSAT-2 data (Lievens, 2012) gave encouraging results over bare soils but not on moderately or densely vegetated areas. Resently, the models for soil moisture retrieval have considered the effects of vegetation cover and surface roughness. Wang and $\mathrm{Qu}$ (2007) designed the normalized multiband drought index (NMDI) for remotely sensing both soil and vegetation water content from space based on the soil and vegetation spectral signatures. Pierdicca et al. (2010) proposed a new method to retrieve soil moisture content over vegetated fields by correcting the vegetation effects based on the integration of the temporal series of radar data within an inversion scheme. Pause et al. (2014) improved soil moisture retrieval from airborne L-band radiometer data by parameterized the surface roughness, based on a radiative transfer model. Clearly, any spectral domain (e.g. optical reflectance, thermal infrared or microwave) has its own limitations and no one is used to predict routinely soil moisture. But the optical reflectance domain is the most operational one, as images are easily available at a broad range of ground resolutions However, in coal mining zone the complexity of surface deformation and the fact that influences the soil reflectance may not be effectively minimized, limits the utility of solar reflectance measurements for soil moisture content determination. So far there is no efficient model to monitor the soil moisture content in coal mining areas using remote sensing techniques. The important issues are therefore the timing for an efficient observation of soil moisture, the identification of the model in optimum conditions and the variation of the model with the soil type and the ground resolution.

The major objective of this study is to develop a retrieval model that is acceptable to estimate soil moisture quickly in the whole coal mining zone of Northern of Shaanxi based upon the soil sample parameters collected from the field, spectral data gathered simultaneously and the different phase Landsat 7 and Landsat 8 data, analyze the patterns of spatial and temporal variations of soil moisture caused by ground deformation in the coal mining areas. The results can serve as the bases for the restoration and protection of local ecological environment.

\section{STUDY AREA AND DATA}

\subsection{Study area}

As the study area, Daliuta mining is belonged to the Shenmu county, Yulin city, which is located at the northernmost part of Shaanxi province and near the Inner Mongolia Autonomous Region border. The longitude and latitude of the study region are $110^{\circ} 05^{\prime}-110^{\circ} 20^{\prime} \quad$ E, $39^{\circ} 15^{\prime}-39^{\circ} 29^{\prime} \quad \mathrm{N}$. The Daliuta mining area is a modern super-huge coal mine and has an annual output of raw coal of more than 10 million tonnes, which plays an important role in the exploitation of coal resources.

\section{2 in situ spectral reflectance data and soil moisture data}

On July 23th-24th, 2009, the workgroup designed seven sections near Daliuta mining area to collect field data. 42 sample sites were located perpendicular to the sections in the typical deformation areas, including a single fissure, multi-fissures and collapse sites. On each site, the soil samples about the distance of
$10 \mathrm{~cm}$ under the ground surface were gathered. Then the soil moisture content was tested in the laboratory. The results showed that the maximum level of soil moisture in 42 samples was $4.49 \%$, the minimum was $0.73 \%$, and the mean was $1.66 \%$. On each site, soil reflectance was measured simultaneously by a spectrometer of double channel manufactured by Analytical Spectral Devices (ASD) of the United States. The spectral range covers the spectrum of $350 \mathrm{~nm} \sim 2500 \mathrm{~nm}$. The observation geometry is adopted from the method that the observation angle with the sun incident plane is 90 to 135 degrees and 40 degrees with the ground normal. Surveying time was from 9:30 am to 14:30 pm. For each observation, 20 survey curves were recorded.

\subsection{RS data}

Two-phase Landsat7 ETM data of 2002, 2009 and a phase Landsat 8 OLI data of 2015 of the study area, were adopted to retrieval soil moisture information. The RS images were pre-processed for atmospheric radiometric using FLAASH (fast line-of-sight atmospheric analysis of spectra hypercubes), an atmospheric correction module in ENVI ${ }^{\circledR}$ software, and geometric corrections based on control points that were identified on the topographic map at a scale of 1:10,000 using ERDAS 9.2, an RS images processing system. The root mean square error (RMSE) for positional accuracy was generally less than 1 pixel $(30 \mathrm{~m})$. A nearest-neighbor resampling method was used to preserve the original digital numbers (DNs) of the image.

\section{METHODOLOGY}

\subsection{Soil moisture spectral characteristics and the sensitive bands}

Based upon the spectral data gathered from 42 samples sites, residual curves were derived by the average values. The reflectance spectral characteristic curves of section 2 were shown in Figure 1.

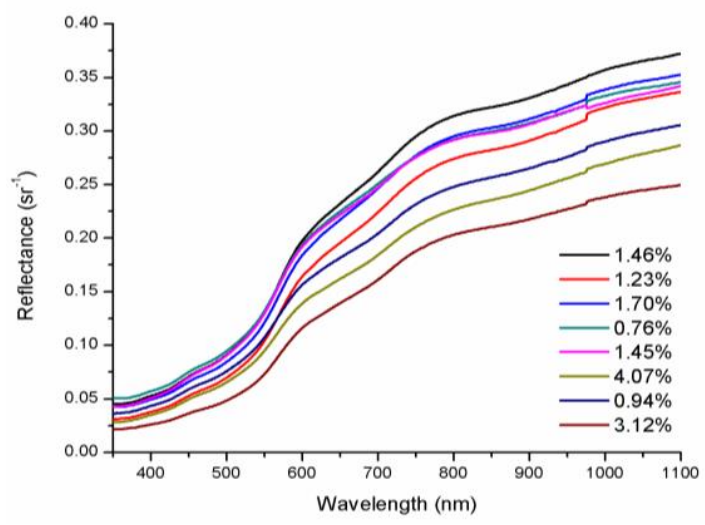

Figure 1. The spectral characteristic curves of the soil

Figure 1 showed that the soil spectral reflectance levels increased with the wavelength in the band region of $450-1100 \mathrm{~nm}$. At a given wavelength, the reflectance level decreased with increasing soil moisture content. The reflectance difference increased with the wavelength over the band region of $600 \mathrm{~nm}$. and it was more obvious over $800 \mathrm{~nm}$. Distinctly, the long wavelength in visible and near-infrared bands was more sensitive to soil moisture.

Considering the effect of the representation of ground deformation on remote sensing images in the study area and 
removing the influence produced by vegetation in the process of soil moisture retrieval, Spectrum Method will be adopted for soil moisture retrieval (Liu et al 1997). Compared with the bands of Landsat7 satellite sensors, the appropriate bands to soil moisture retrieval using Spectrum Method are in region of visible and near-infrared wavelengths, as the bands of ETM1, ETM2, ETM3 and ETM4. Spectral reflectance of all points are re-sampled to the centre wavelength of ETM1, ETM2, ETM3 and ETM4 for get remote sensing reflectance $\operatorname{Rrs}_{1}, \mathrm{Rrs}_{2}, \mathrm{Rrs}_{3}$ and $\mathrm{Rrs}_{4}$. In order to select significant bands that are sensitive to soil moisture levels, the Pearson Correlation Coefficients between the soil moisture levels and the reflectivity levels of individual band $\mathrm{Rrs}_{1}-\mathrm{Rrs}_{4}$ were calculated. A wide range of correlation coefficients, from -0.369 to -0.801 , was obtained. $\mathrm{Rrs}_{4}$ is the most sensitive variable and is chosen for further analysis.

\subsection{Soil moisture retrieval model}

Regression analysis is the most common modeling approach to describe the relationship between soil moisture and spectral data, and therefore, it is also adopted in this study. Based upon the previous correlation analysis, $\mathrm{Rrs}_{4}$ is the sensitive factor that may be used to estimate soil moisture levels. Among data gathered from the original 42 sampled locations in 2009, only 36 sampled locations were retained for subsequent analysis. In order to calibrate and validate the relationships between soil moisture levels and the sensitive factor, soil moisture levels for the 24 sampled locations out of the total 36 valid sampling points were used to establish quantitative retrieval models of soil moisture with reflectance data $\operatorname{Rrs}_{4}$. Data for the remaining 12 sampling locations were reserved for model validation. For the sensitive factor $\mathrm{Rrs}_{4}$, five types of model including Linear, Logarithmic, Quadratic, Power and Exponential Models, were developed to evaluate its relationship with soil moisture levels. Specifications of the models and regression results are reported in Table 1. Quadratic model has the highest $R^{2}\left(R^{2}=0.802\right)$. Therefore, the quadratic model is proposed as the soil moisture retrieval model for the study area.

\begin{tabular}{|c|l|l|c|}
\hline No. & Model type & \multicolumn{1}{|c|}{ Model } & $\mathrm{R}^{2}$ \\
\hline 1 & Linear & $\mathrm{Y}=-15.149 * \mathrm{X}+5.622$ & 0.642 \\
2 & Logarithmic & $\mathrm{Y}=-3.675 * \ln \mathrm{X}-3.36$ & 0.731 \\
3 & Quadratic & $\mathrm{Y}=92.348 * \mathrm{X}^{2}-60.66 * \mathrm{X}+10.938$ & 0.802 \\
4 & Power & $\mathrm{Y}=0.141 * \mathrm{X}^{-1.675}$ & 0.553 \\
5 & Exponential & $\mathrm{Y}=8.76 * \mathrm{e}^{(-7.035 * \mathrm{X})}$ & 0.504 \\
\hline
\end{tabular}

Note: $y$ is soil moisture, $x$ is $\operatorname{Rrs}_{4}$.

Table 1. The regression models for soil moisture retrieval

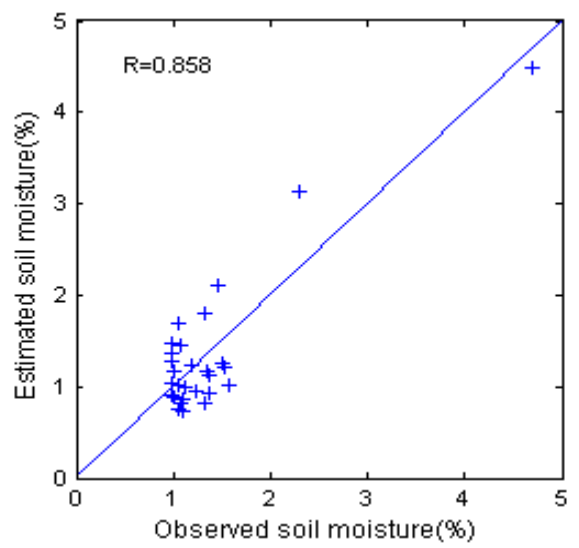

Figure 2. The relationship between observed and estimated soil moisture of 2009
To evaluate the performance of the retrieval model identified above, we used it to estimate the soil moisture levels based upon $\mathrm{Rrs}_{4}$ of the remaining 12 samples. The estimated soil moisture levels were compared with the values observed from the field. Their differences can be treated as residuals. The accuracy of the model is acceptable with a mean residual of $0.49 \%$, a mean relative error of $32.77 \%$ and a root-mean-squared error (RMSE) of $0.59 \%$. As shown in Figure 2, estimated soil moisture levels are related to the values observed from the fields. The correlation coefficient is 0.858 .

\subsection{Soil moisture retrieval using different phase RS data}

3.3.1 The radiant calibration of historical image pixel value: There was radiation difference between two-phase remote sensing images because of the different imaging conditions. Different phase images must be calibrated for the radiation to ensure that the soil moisture levels of inversed in different time are consistency and reliability. The common method of radiant calibration is to develop the models based on correlation analysis using the historical image pixel value of invariant ground targets. So, the image pixel values of 20 invariant ground points were adopted to analyze the correlation between the images of 2002 and 2009, as well as 2009 and 2015, respectively, and then developed the radiant calibration model as follows:

$$
\begin{aligned}
& R_{2009}=0.987 * R_{2002}-0.0261 \quad\left(R^{2}=0.98\right) \\
& R_{2009}=1.02 * R_{2015}+0.0231 \quad\left(R^{2}=0.99\right)
\end{aligned}
$$

where $R_{2002}, R_{2009}$ and $R_{2015}$ are the reflectance of $R S$ images correspond to 2002, 2009 and 2015 respectively.

The image pixel value of 2002 and 2015 can be calibrated to the value of 2009 equivalently by the formula (1) and (2).

3.3.2 Optical vegetation coverage model: Soil moisture retrieval model by spectral method is an expression of soil water content and corresponding spectral brightness for bare soil. But the image pixel values of RS data are always the mixture of soil and vegetation spectrum. To get bare soil spectral value of each pixel, the influence of vegetation on soil spectrum must be eliminated. The "optical vegetation coverage" model, defined as the ratio of actual vegetation optical information to total vegetation optical information was used to eliminate the influence of vegetation. The calculation of optical vegetation coverage for Landsat7 ETM pixel can be performed with spectral reflectance of band2, 3 and 4 (the optical vegetation coverage for Landsat8 OLI pixel can be expressed with spectral reflectance of band3, 4 and 5), take ETM data for example, The formula is as follows:

$$
C_{v o}=\frac{R_{4}-R_{23}-r_{s o}}{R_{4 v}-R_{23 v}-r_{s o}}
$$

where $\mathrm{C}_{\mathrm{vo}}$ is the optical vegetation coverage of pixel

$\mathrm{R}_{4}$ is the spectral reflectance of band4

$R_{23}$ is the average spectral reflectance of band 2 and band3

$\mathrm{R}_{4 \mathrm{v}}$ is the spectral reflectance of band 4 under the ideal condition of the pixel purely covered with vegetation

$\mathrm{R}_{23 \mathrm{v}}$ is the average spectral reflectance of band 2 and band 3 in the ideal condition of the pixel purely covered with vegetation

$r_{s o}$ is a constant, equal to the difference between $R_{4}$ and $\mathrm{R}_{23}$ of bare soil 
The RS reflectance is a composite in a pixel that is covered with soil and vegetation. Take band4 of ETM data for example, the soil spectral reflectance can be calculated as follows:

$$
R_{4 S}=\frac{R_{4}-C_{v o} R_{4 v}}{1-C_{v o}}
$$

where $R_{4 s}$ stands for the soil spectral reflectance of each pixel.

Formula (4) provides an estimate method that transforms the composite information into spectral reflectance of bare soil, to eliminate the influence of vegetation on soil spectrum. The method is adapted directly to bare soil.

In order to get the soil spectral reflectance of ETM band of 2002 2009 and OLI band of 2015, 20 samples of bare soil and 20 of high covered vegetation (considered as purely vegetation samples) were selected for statistics analysis. The results were showed in Table 2.

\begin{tabular}{|c|c|c|c|c|}
\hline Time & $\mathbf{R}_{\mathbf{4 v}}$ & $\mathbf{R}_{\mathbf{2 3 v}}$ & $\mathbf{R}_{\mathbf{4 s}}$ & $\mathbf{R}_{\mathbf{2 3 s}}$ \\
\hline 2002 & 0.3757 & 0.0483 & 0.3701 & 0.2321 \\
2009 & 0.3629 & 0.0400 & 0.3499 & 0.2168 \\
2015 & 0.3149 & 0.0519 & 0.3215 & 0.1931 \\
\hline
\end{tabular}

Table 2. The spectral reflectance of ETM band of 2002 and 2009, as well as OLI band of 2015

Based upon the parameters in table 2, the soil spectral reflectance corresponding to ETM4 of 2002 and 2009 as well as OLI5 of 2015 were calculated by formula (5) (6)and (7):

$$
\begin{aligned}
& R_{4 s(2002)}=\frac{R_{4}-C_{v o} R_{4 v}}{1-C_{v o}}=\frac{1.1335 B_{2}+0.8501 B_{3}-0.9836 B_{4}+0.2737}{3.017 B_{2}+2.2628 B_{3}-5.2798 B_{4}+1.7286} \\
& R_{4 s(2009)}=\frac{R_{4}-C_{v o} R_{4 v}}{1-C_{v o}}=\frac{1.0926 B_{2}+0.8194 B_{3}-0.9120 B_{4}+0.2545}{3.0107 B_{2}+2.2580 B_{3}-5.2687 B_{4}+1.7013} \\
& R_{5 s(2015)}=\frac{R_{5}-C_{v o} R_{5 v}}{1-C_{v o}}=\frac{1.3369 B_{3}+1.0026 B_{4}-1.3395 B_{5}+0.3004}{4.2454 B_{3}+3.1840 B_{4}-7.4294 B_{5}+1.9539}
\end{aligned}
$$

3.3.3 Soil moisture retrieval using different phase RS data: The soil moisture was estimated using the retrieval model (formula (8)) after eliminating the influence of vegetation by formula (5) (6) and (7).

$$
\mathrm{Y}=92.348 * X^{2}-60.66 * X+10.938
$$

where $\mathrm{X}$ is $\mathrm{Rrs}_{4}$ for Landsat7 or $\mathrm{Rrs}_{5}$ for Landsat8 after eliminating the influence of vegetation $\mathrm{Y}$ is the retrieved soil moisture value

In order to evaluate the retrieval precision for soil moisture, 12 check points were selected from Landsat7 ETM images of 2009 corresponding to soil samples in study area. The inversed and observed values of soil moisture were compared to evaluate the retrieval accuracy. The differences can be treated as residuals. The result showed that the mean residual was $0.52 \%$, mean relative error was $35.16 \%$ and the root-mean-squared error (RMSE) was $0.58 \%$.

\section{RESULTS AND DISCUSSION}

Daliuta mining area was taken as the principal study range. According to the estimated values, soil moisture levels were divided into 5 grades, including lower, low, middle, high and higher levels (as shown in Table 3). Based upon the divided grades of soil moisture contents, the distribution maps of retrieved soil moisture of 2002, 2009 and 2015 were drawn as Figure 3.

\begin{tabular}{|c|c|c|c|c|c|}
\hline Grade & Lower & Low & Middle & High & Higher \\
\hline $\begin{array}{c}\text { Soil moisture } \\
(\%)\end{array}$ & $0 \sim 1$ & $1 \sim 1.5$ & $1.5 \sim 2.5$ & $2.5 \sim 3$ & $>3$ \\
\hline
\end{tabular}

Table 3. The divided grades of soil moisture levels

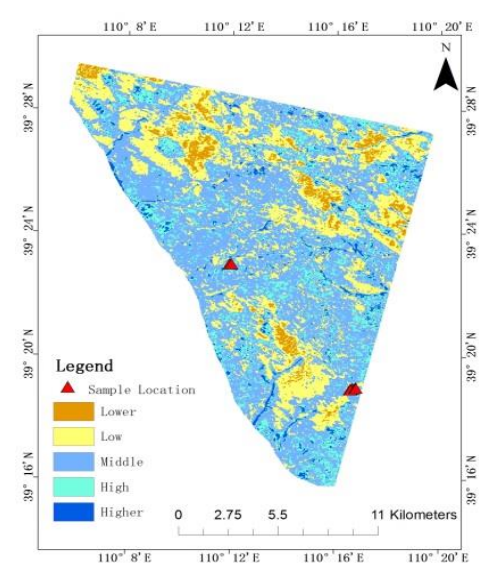

(a)

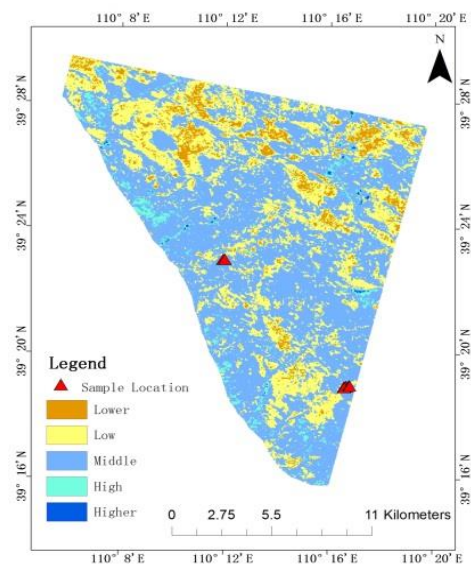

(b)

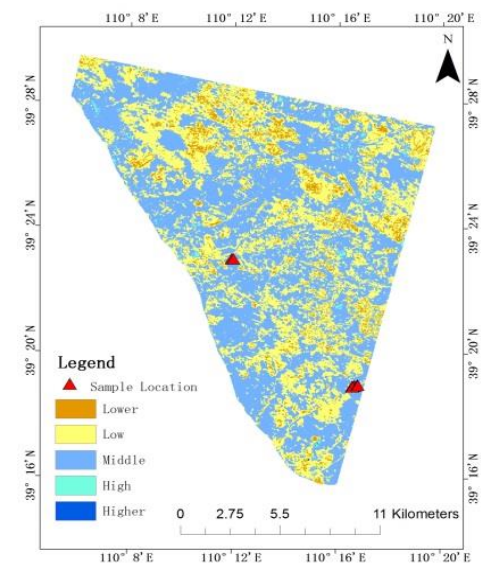

(c)

Figure 3. The distribution maps of retrieved soil moisture of 2002(a), 2009(b) and 2015(c)

In order to further analyze the changed status of soil moisture content, the transfer matrix of soil area with different moisture level between 2002 and 2009 as well as 2009 and 2015 were established by formula (9) based upon the modeling function of ERDAS9.2 software.

$$
N C(i, j)=N C(i) * 10+N C(j)
$$

where $\mathrm{NC}(\mathrm{i}, \mathrm{j})$ is the pixel value of changed soil moisture distribution map corresponding to $\mathrm{i}, \mathrm{j}$ two-phase $\mathrm{NC}(\mathrm{i})$ is the pixel value of soil moisture distribution map corresponding to i phase 
$\mathrm{NC}(\mathrm{j})$ is the pixel value corresponding to $\mathrm{j}$ phase

Table 4 and Table 5 show the calculating results of transfer matrix of soil moisture for 2002 to 2009 and 2009 to 2015 , respectively. Clearly, from 2002 to 2009 , most regions with high moisture level were converted to middle or low moisture content areas and the regions with middle moisture levels were converted to low moisture content areas from 2009 to 2015. In general, the soil moisture level showed a decreased trend from 2002 to 2015 .

\begin{tabular}{|l|c|c|c|c|c|c|}
\hline 2009 & Lower & Low & Middle & High & Higher & Total \\
\hline Lower & 6.98 & 6.51 & 0.75 & 0.14 & 0.13 & 14.51 \\
Low & 5.36 & 52.87 & 17.97 & 1.75 & 1.25 & 79.21 \\
Middle & 0.12 & 13.83 & 111.81 & 30.18 & 5.93 & 161.87 \\
High & 0.005 & 0.22 & 2.11 & 3.49 & 1.87 & 7.68 \\
Higher & 0.003 & 0.06 & 0.19 & 0.15 & 0.16 & 0.56 \\
Total & 12.47 & 73.49 & 132.83 & 35.71 & 9.34 & 263.84 \\
\hline
\end{tabular}

Table 4. The transfer matrix of soil area with different moisture levels from 2002 to 2009 (area $/ \mathrm{km}^{2}$ )

\begin{tabular}{|l|c|c|c|c|c|c|}
\hline 2015 & Lower & Low & Middle & High & Higher & Total \\
\hline Lower & 4.52 & 5.01 & 3.80 & 0.12 & 0.02 & 13.46 \\
Low & 9.20 & 53.67 & 37.62 & 1.16 & 0.13 & 101.78 \\
Middle & 0.75 & 20.28 & 119.49 & 6.14 & 0.29 & 146.95 \\
High & 0.03 & 0.21 & 0.92 & 0.26 & 0.12 & 1.55 \\
Higher & 0.01 & 0.03 & 0.05 & 0.005 & 0 & 0.09 \\
Total & 14.51 & 79.21 & 161.87 & 7.68 & 0.56 & 263.84 \\
\hline
\end{tabular}

Table 5. The transfer matrix of soil area with different moisture levels from 2009 to 2015 (area $/ \mathrm{km}^{2}$ )

The analysis method of difference calculation between two-phase RS data was proposed in this paper to reveal the spatial changes of ground features. The differences of spatial distribution of soil moisture content between 2002 and 2009 as well as 2009 and 2015 were estimated based on the retrieved soil moisture. According to the difference of soil moisture, the changed levels are divided into 4 grades, i.e. increased, slight-decreased, moderate-decreased and severe-decreased. The spatial distribution of different changed levels for soil moisture content between 2002 and 2009 as well as 2009 and 2015 were shown in Figure 4.

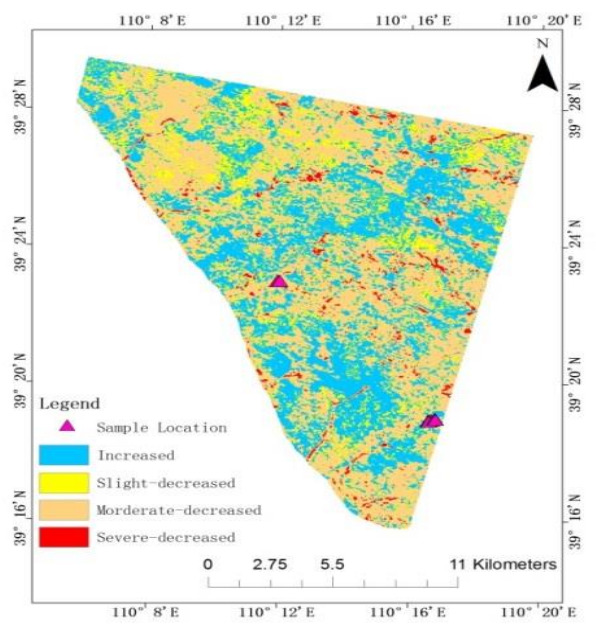

(a)

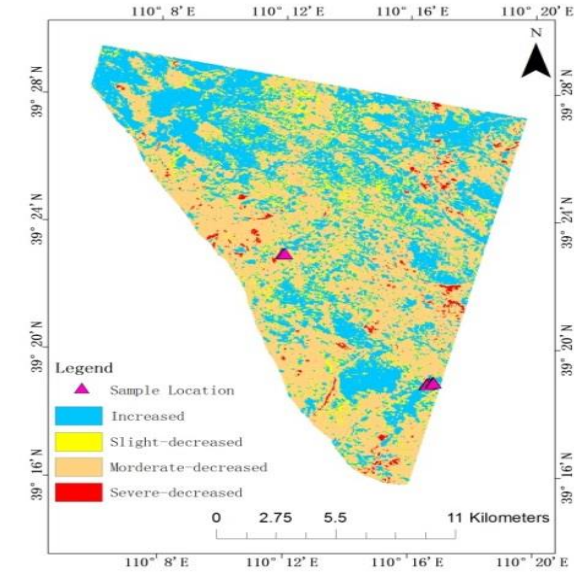

(b)

Figure 4. The changes of soil moisture from 2002 to 2009 (a) as well as from 2009 to 2015 (b)

Compared with the differences of soil moisture from 2002 to 2009 and 2009 to 2015, the regions of increased levels were enlarged and severe decreased areas were reduced slightly. The result is consistently with the coal mining scale, i.e. it was extensive from 2002 to 2009 and shrunken from 2009 to 2015.

\section{CONCLUSIONS}

The correlation analysis between measured soil moisture and RS reflectance showed that near-infrared band was the sensitive band for soil moisture retrieval in coal mining area of Northern Shaanxi. And a quadratic pattern was the best model in the area with the correlation coefficient of 0.858 between observed and estimated soil moisture. The precision of retrieved soil moisture was acceptable with the mean residual of $0.52 \%$, mean relative error of $35.16 \%$ and the root mean squared error (RMSE) of $0.58 \%$. Two-phase Landsat7 ETM data of 2002 and 2009 and one phase Landsat 8 OLI data of 2015 of the study area were selected to retrieval soil moisture information, and the results showed that the spatial distribution of soil moisture content were decreased in general from 2002 to 2015. However, compared with the differences of soil moisture for 2002 to 2009 and 2009 to 2015 , the regions of increased levels were enlarged and severe decreased areas were reduced slightly. It is consistently with the coal mining scale in different period. The study method can serve as the baseline for monitoring soil moisture timely in the future.

\section{ACKNOWLEDGEMENTS}

The financial supports from the National Natural Science Foundation of China (Grant No.41272246), the Key Project of Education Department of China (Grant No.108183) and the Special Fund for Basic Scientific Research of the Central University, China (Grant No.2013G3272013) are gratefully acknowledged. The authors also would like to thank Key Laboratory of Subsurface Hydrology and Ecology in Arid Areas of Education Ministry, China that provided the good conditions for finishing the experiments and processing collected data. 


\section{REFERENCES}

Duan, S.-B.; Li, Z.-L.; Tang, R.-L.; Tang, B.-H.; Wu, H.; Jiang, X.-G., 2014. Temporal-spatial variations monitoring of soil moisture using microwave polarization difference index. In: IEEE Geoscience and Remote Sensing Symposium. (IGARSS). Proceedings, Quebec City, QC, Canada, pp. 3292-3295.

El-Hajj, M.; Baghdadi, N.; Belaud, G.; Zribi, M.; Cheviron, B.; Courault, D.; Charron, F., 2014. Soil moisture retrieval over grassland using X-band SAR data. In: IEEE Geoscience and Remote Sensing Symposium. (IGARSS). Proceedings, Quebec City, QC Canada, pp. 3638-3641.

Escadafal, R.; Girard, M.-C.; Courault, D., 1989. Munsell soil color and soil reflectance in the visible spectral bands of landsat MSS and TM data. Remote Sensing of Environment, 27(1), pp. 37-46.

Han, XJ.; Duan, S.-B.; Tang, R.-L.; Liu, H.-Q.; Li, Z.-L., 2015. Evaluation of temporal variations in soil moisture based on the microwave polarization difference index using in situ data over agricultural areas in China. International Journal of Remote Sensing, 36(19-20), pp.5003-5014.

Hoffer, R.-M.; Johannsen, C.-J., 1969. Ecological potentials in spectral signature analysis. In P. L. Johnson [ed.] Remote sensing in ecology, University of Georgia, Athens, Georgia, USA, pp. 1-16.

Hovis, W.-A., 1966. Infrared Spectral Reflectance of Some Common Minerals. Applied Optics, 5(2), pp. 245-248.

Jacquemoud, S.; Baret, F.; Hanocq, J.-F., 1992. Modeling spectral and bidirectional soil reflectance. Remote Sensing of Environment, 41(2-3), pp. 123-132.

Jian, J.; Yang, W.; Jiang, H.; Wan, X.; Li, Y., 2012. A model for retrieving soil moisture saturation with Landsat remotely sensed data. International Journal of Remote Sensing, 33(14), pp. 4553-4566.

Leng, P.; Song, X.-N.; Li, Z.-L.; Ma, J.-W.; Zhou, F.-W.; Li S., 2014. Bare surface soil moisture retrieval from the synergistic use of optical and thermal infrared data. International Journal of Remote Sensing, 35(3), pp. 988-1003.

Leng, P.; Song, X.-M. Li, Z.-L.; Wang, Y.-W.; Wang, R.-X., 2015. Toward the Estimation of Surface Soil Moisture Content Using Geostationary Satellite Data over Sparsely Vegetated Area. Remote Sensing, 7(4), pp. 4112-4138.

Li, Z.-L.; Tang, B.-H.; Wu, H.; Ren, H.-Z.; Yan, G.-J.; Wan, Z.-M.; Isabel, F.-T.; José, A.-S., 2013. Satellite-derived land surface temperature: Current status and perspectives. Remote Sensing of Environment, 131, pp. 14-37.

Lievens, H.; Verhoest, N.-E.-C., 2012. Spatial and temporal soil moisture estimation from RADARSAT-2 imagery over Flevoland, The Netherlands. Journal of Hydrology, 456-457(16), pp. 44-56.

Liu, P.-J.; Zhang, L.; Kurban A.-C. et al., 1997. The method of estimate soil moisture by Remote sensing. Remote sensing learned journal, 1(2), pp. 135-138.

Liu, Z.-L.; Tang, B.-H.; Qiu, S.; Li, Z.-L., 2014. An Empirical Relationship of Bare Soil Microwave Emissions Between Vertical and Horizontal Polarization at $10.65 \mathrm{GHz}$. IEEE
Geoscience and Remote Sensing Letters, 11(9), pp. 1479-1483.

Lobell, D.-B.; Asner, G.-P., 2002. Moisture Effects on Soil Reflectance . Soil Science Society of America Journal, 66(3), pp.722-727.

Mattikalli, N.-M., 1997. Soil color modeling for the visible and near-infrared bands of Landsat sensors using laboratory spectral measurements. Remote Sensing of Environment, 59(1), pp. 14-28.

Mladenova, I.-E.; Jackson, T.-J.; Njoku, E.; Bindlish, R.; Chanb, S.; Cosha, M.-H. et al., 2014. Remote monitoring of soil moisture using passive microwave based techniques theoretical basis and overview of selected algorithms for AMSR-E. Remote Sensing of Environment, 144, pp. 197-213.

Moran, M.-S.; Peters-Lidard, C.-D.; Watts, J.-M.; McElroy , S., 2004. Estimating soil moisture at the watershed scale with satellite-based radar and land surface models. Canadian Journal of Remote Sensing, 30(5), pp. 805-826.

Pause, M.; Lausch, A.; Bernhardt, M,; Hacker, J.; Schulz, K., 2014. Improving Soil Moisture Data Retrieval From Airborne L-Band Radiometer Data by Considering Spatially Varying Roughness. Canadian Journal of Remote Sensing, 40(1), pp. $15-25$.

Pierdicca, N.; Pulvirenti, L.; Bignami, C., 2010. Soil moisture estimation over vegetated terrains using multitemporal remote sensing data. Remote Sensing of Environment, 114(2), pp. 440-448.

Rincon, R.-F.; Fatoyinbo, T.; Ranson, K.-J.; Osmanoglu, B.; Sun, G.; $\quad$ Deshpande, M.; Perrine, M.; Toit, C.-D.; Bonds, Q.; Beck, J.; Lu, D., 2014. The Ecosystems SAR (EcoSAR) an Airborne P-band Polarimetric InSAR for the Measurement of Vegetation Structure, Biomass and Permafrost. In: IEEE Radar Conference. Proceedings, Cincinnati, OH, United States, pp.1443-1445.

Sadeghi, M.; Jones, S.-B.; Philpot, W.-D., 2015. A linear physically-based model for remote sensing of soil moisture using short wave infrared bands. Remote Sensing of Environment, 164, pp. 66-76.

Skidmore, E.-L.; Dickerson, J.-D.; Schimmelpfennig, H., 1975. Evaluating surface-soil water content by measuring reflectance. Soil Science Society of America Journal, 39(2), pp. 238-242.

Song, Y. -X., 2007. Soil water migration and environment effect in Shenfu-Dongsheng subsidence area. ph.D. thesis, Chinese Academy of Geological Sciences, Beijing, China.

Stoner, E.-R.; Baumgardner, M.-F., 1981. Characteristic variations in reflectance of surface soils. Soil Science Society of America Journal, 45(6), pp. 1161-1165.

Wang, L.; Qu, J.-J., 2007. NMDI: A normalized multi-band drought index for monitoring soil and vegetation moisture with satellite remote sensing. Geophysical Research Letters, 34(20), pp. L20405.

Zhao, W.; Li, Z.-L.; Wu, H.; Tang, B.-H.; Zhang, X.-Y.; Song, X.-N.; Zhou. G.-Q., 2013. Determination of bare surface soil moisture from combined temporal evolution of land surface temperature and net surface shortwave radiation. Hydrological Processes, 27(19), pp. 2825-2833. 